\title{
Desigualdade escolar e vulnerabilidade social no território*
}

\section{School inequality and social vulnerability in the territory}

\author{
Vanda Mendes Ribeiro** \\ Cláudia Lemos Vóvio***
}

\begin{abstract}
RESUMO
Este texto discute resultados de pesquisas sobre a influência da vulnerabilidade social nos territórios das grandes cidades na produção da desigualdade escolar, realizadas em duas metrópoles brasileiras. Tais pesquisas têm recorrido à literatura da Cepal, da Sociologia da educação francesa e norte-americana na busca de referências para lidar com um fenômeno recentemente transformado em problema de pesquisa. As pesquisas evidenciam que a vulnerabilidade social do território interfere nas oportunidades educacionais. Detectaram mecanismos capazes de produzir vínculos entre vulnerabilidade social do território e produção da desigualdade escolar, tais como relações de interdependência competitiva entre escolas, falta de investimento do Estado na Educação Infantil, representações sociais desfavoráveis às populações residentes nessas áreas das cidades e falta de equipamentos públicos nos territórios vulneráveis. Os estudos mostraram que os contornos das políticas educacionais podem fomentar a desigualdade escolar em territórios vulneráveis: professores, com mais experiência e formação, migram para
\end{abstract}

DOI: $10.1590 / 0104-4060.51372$

* A realização desse estudo contou com o financiamento da Fundação Tide Setúbal e do Conselho Nacional de Desenvolvimento Científico e Tecnológico $(\mathrm{CNPq})$ por meio de projeto financiado, MCTI/CNPq/Universal 14/2014; e também com a colaboração de Antônio Augusto Gomes Batista, de Hivy Damazio de Araújo Mello e Joana Buarque de Gusmão, pesquisadores do Centro de Estudos e Pesquisas em Educação, Cultura e Ação Comunitária (Cenpeq). Nossos agradecimentos

** Universidade Cidade de São Paulo. Programa de Pós-Graduação em Educação e Formação de Gestores Educacionais. São Paulo, São Paulo, Brasil. Rua Honório Maia, 145, Tatuapé. CEP: 03070-010. E-mail: vandaribeiro2@gmail.com.

${ }_{* * *}$ Universidade Federal de São Paulo. Departamento de Educação. Guarulhos, São Paulo, Brasil. Estrada do Caminho Velho, 353, Jardim Nova Cidade. CEP: 04021-00. E-mail: cl.vovio@unifesp.br. 
escolas de territórios menos vulneráveis devido à legislação dos concursos de remoção; alunos com menor capital sociocultural, cujos pais ignoram o tipo de capital social valorizado pela escola, que desconhecem seus direitos e que residem em territórios estigmatizados, como favelas, podem ser preteridos em momentos de matrícula, dificultando seu acesso à escola. Em atos de expulsão de alunos, esses estigmas podem contribuir para a decisão, uma vez que escolas parecem buscar alunos mais adaptados a um ambiente escolar menos conturbado.

Palavras-chave: Vulnerabilidade social. Desigualdade escolar. Território. Política educacional.

\begin{abstract}
The aim of the following study is to discuss the results of studies about the influence of social vulnerability on school inequality in big cities, carried out in two Brazilian metropolises. Those studies have resorted to ECLAC literature, as well as French and American Sociology of Education literature, in order to find references to approach a phenomenon that has recently become a research problem. According to the herein investigated studies, the territory's social vulnerability affects educational opportunities. They have found mechanisms able to produce links between the territory's social vulnerability and school inequality, such as relations of competitive interdependence between schools, the lack of state investment in early childhood education, social representations unfavorable to people living in these areas, and the lack of public facilities in vulnerable territories. The studies have shown that educational policy contours may foster school inequality in vulnerable territories. More experienced and better trained teachers migrate to schools located in less vulnerable territories due to the transference program legislation. Students with less socio-cultural capital, whose parents are less aware of the type of social capital valued by the school, who are unaware of their rights, and live in the most stigmatized territories such as slums, may be passed over at school enrollment times, which may hinder their access to education. In the case of students expelled from schools, this stigma may contribute to the decision-making process, since schools seem to prefer students who are better adapted to less-troubled school environments.
\end{abstract}

Keywords: Social vulnerability. School inequality. Territory. Educational policy. 


\section{Introdução}

Este texto discute resultados de pesquisas sobre a influência da vulnerabilidade social nos territórios das grandes cidades na produção da desigualdade escolar, realizadas em duas grandes cidades brasileiras. Os estudos aqui analisados se baseiam na noção de vulnerabilidade social proposta por Kaztman (2001), ex-oficial da Comissão Econômica para a América Latina e o Caribe (Cepal); em literatura francesa como Ben Ayed e Broccolichi (2008); e em conceitos da literatura norte-americana sobre segregação residencial, efeito de pares e de vizinhança.

De acordo com Kaztman (2001), o modo como se deu a ocupação do solo urbano nas grandes cidades na América Latina gerou um fenômeno de sobreposições de desigualdades que leva ao distanciamento de populações dos códigos e normas que predominam no restante da cidade, acentuando o isolamento social. Para Kaztman (2001), o isolamento de certos territórios permite menos informações e contatos; há menor nível de eficiência normativa; menor exposição a modelos de diversos papéis sociais; as populações têm vínculos precários com o trabalho e com os serviços, públicos e privados. Assim, parte das populações das grandes cidades se distancia do valor democrático da mobilidade social, tanto em termos reais, no que tange ao deslocamento físico das pessoas, quanto em termos simbólicos, no que concerne às expectativas de melhoria do seu bem-estar social.

Ben Ayed e Broccolichi (2008) buscam compreender a relação entre concentração de populações de características sociais desfavoráveis similares e educação por meio do conceito de desigualdades socioespaciais. Essas desigualdades se reportam, para os autores, à segregação das populações de modo que os espaços de residência passam, devido a processos históricos e demográficos, a expressar também propriedades sociais, econômicas e culturais. Os estudos que relacionam esse fenômeno à educação objetivam, para os autores, apreender as variações nas aquisições escolares entre as populações residentes em distintos espaços urbanos.

Koslinski e Alves (2012, p. 810) afirmam que "os estudos que partem do conceito de efeito vizinhança focalizam o impacto da concentração da pobreza sobre desfechos escolares individuais". Também reiteram que esses conceitos são originários de estudos urbanos da escola de Chicago (EUA) que "argumentavam que as cidades estão divididas em áreas que apresentam características físicas e culturais diferentes, ou seja, em contextos sociais caracterizados por normas e significados que são diferentes e persistem ao longo do tempo". Citam 
também o trabalho do norte-americano Wilson (1987) como referência central do conceito de efeito vizinhança. A relação entre a segregação residencial e/ou a concentração da pobreza urbana e comportamentos individuais é explicitada pelas autoras do seguinte modo: "a concentração de pobreza [e o isolamento social] desconecta[m] as pessoas de laços sociais com a classe média e, portanto, com a cultura "mainstream"” (KOSLINSKI; ALVES, 2012, p. 811).

Koslinski e Alves identificaram na literatura norte-americana diferentes modos de abordar a questão da segregação das populações nas cidades. Citam Jencks e Mayer (1990), para os quais o comportamento dos pares que vivem no mesmo território "contagiaria" as pessoas, constituindo então o modelo efeito de pares. Para elas, há também linhas de pesquisas mais focadas em compreender a socialização em sua forma coletiva - crescer em áreas segregadas ou muito pobres impediria os indivíduos de terem contato com "modelos de papel social de adultos da classe média, ou de modelos bem-sucedidos, especialmente daqueles desenvolvidos pela via da escolarização" (KOSLINSKI; ALVES, 2012, p. 812). Por fim, haveria ainda os modelos institucionais. Nesse caso, o foco recairia sobre adultos "que trabalham em instituições localizadas no bairro segregado" (KOSLINSKI; ALVES, 2012, p. 812).

Torres et al. (2008) chama a atenção sobre a importância de se diferenciar, na literatura americana, os estudos que focalizam mecanismos que explicam a relação dos indivíduos residentes em territórios vulneráveis com a estrutura de oportunidades, inclusive educacionais, dos estudos que focalizam o modo como as instituições operam na relação com a situação de vulnerabilidade social. Para esse autor, a segunda via seria mais profícua quando se objetiva buscar apontamentos para as políticas educacionais.

Pereira-Silva (2016) afirma que os estudos que visam compreender a conexão entre vulnerabilidade social nos territórios das grandes cidades e a produção da desigualdade escolar denotam a relevância de se ir além das tentativas de compreender tal desigualdade por meio de indicadores que se reportam a uma única dimensão de desigualdade social (de acesso à renda ou relativa às situações de origem, por exemplo). Analisando as conclusões da autora, vê-se que a compreensão dos fenômenos sociais advindos da relação entre vulnerabilidade social, nos territórios das grandes cidades, e a desigualdade escolar exigiriam estudo simultâneo de um conjunto de situações que, associadas, têm potencial de produzir forte desigualdade escolar nos territórios mais desfavorecidos das grandes cidades. 


\section{Principais resultados das pesquisas analisadas}

Os estudos em tela tratam de pesquisas realizadas no município de São Paulo e do Rio de Janeiro. De um lado, têm-se estudos que se concentraram em um território específico como são os estudos realizados por Érnica e Batista (2012), Carvalho-Silva e Batista (2013), Alves et al. (2014) e os que deles decorreram como os de Marcucci (2015), Breches (2015) e Tangerino-Silva (2016). Este conjunto de estudos mantém relações entre si, seja pelo território e o conjunto de escolas participantes desses estudos, seja pelo quadro teórico mobilizado e pelas hipóteses testadas ou por laços entre pesquisadores e centros de pesquisa que as realizaram. Além desse conjunto, em São Paulo, há o estudo de Torres e colaboradores, dedicado à compreensão das diferenças no desempenho escolar de estudantes de escolas localizadas em regiões centrais ou periféricas. E também o de Alves et al. (2015) que, embora realizado em São Paulo, também não se reportou a um único território da cidade. Com foco no Rio de Janeiro, têm-se os estudos de Ribeiro e Koslinski (2009), Koslinski, Alves e Lange (2013) e Barbosa e Sant'Anna (2010).

Érnica e Batista (2012) tratam de pesquisa realizada entre 2009 e 2011 em território classificado como sendo de alta vulnerabilidade social no município de São Paulo. Os autores investigaram o efeito da vulnerabilidade social do território sobre as oportunidades educacionais em escolas nele localizadas. Para caracterizar o território, essa pesquisa fez uso do Índice Paulista de Vulnerabilidade Social $\left(\right.$ IPVS $^{1}$ ), dos setores censitários ${ }^{2}$, considerando-se um raio de $1 \mathrm{~km}$ a partir de cada estabelecimento de ensino. Com vistas a obter informações sobre a presença do Estado no território estudado e também sobre as instituições escolares ali presentes, foram mapeados, por meio de pesquisa quantitativa, os equipamentos que visam assegurar direitos sociais e coletados dados sobre as características de 61 escolas públicas da região estudada - São Miguel Paulista (SMP) - e de seus alunos. Ademais, pesquisa de campo de inspiração etnográfica foi realizada em cinco escolas de Ensino Fundamental das redes estadual e municipal, no ano de 2009. A seleção das escolas deu-se a partir de critérios que

1 O Índice Paulista de Vulnerabilidade Social (IPVS) é calculado pela Fundação Sistema Estadual de Análise de Dados (Seade), órgão ligado ao governo do estado de São Paulo, com base nos dados dos Censos Demográficos do Instituto Brasileiro de Geografia e Estatísticas (IBGE). O IPVS localiza as áreas intramunicipais que abrigam populações mais vulneráveis.

2 O setor censitário - a menor unidade territorial de classificação dos dados calculada pelo IBGE - "é definido a partir do agrupamento de cerca de 300 domicílios", e tem a vantagem de poder reunir esses pequenos agrupamentos em unidades maiores. 
permitissem diferenciar tais instituições em termos de composição de seu corpo discente, de acordo com os recursos culturais familiares, vulnerabilidade social do entorno da escola e desempenho das escolas no Índice de Desenvolvimento da Educação (Ideb) ${ }^{3}$. Além disso, foram feitas entrevistas com os profissionais da educação das escolas e observação do cotidiano escolar.

A partir da observação do desempenho dos alunos, tomando por base os resultados da Prova Brasil ${ }^{4}$, constataram que quanto maior os níveis de vulnerabilidade social do entorno do estabelecimento de ensino, mais limitada tende a ser a qualidade das oportunidades educacionais por ele oferecidas. A principal evidência de efeito território sobre as oportunidades educacionais encontrada por esses pesquisadores - notada por meio de procedimentos estatísticos - é que os alunos com baixos recursos culturais familiares que estudam em escolas de entorno mais vulnerável tendem a obter desempenho pior; em contrapartida, alunos com mesmos recursos culturais, quando estudam em contextos menos vulneráveis, obtêm desempenho melhor. A situação é equivalente para alunos com maiores recursos culturais: quando estudam em contextos mais vulneráveis, tendem a apresentar desempenhos piores.

A pesquisa identificou ainda mecanismos que potencializam o efeito território: a) o fato de a escola ser praticamente o único equipamento público nessas localidades, dificultando o acesso da população aos serviços públicos e a outros recursos culturais socialmente valorizados, sobrecarregando assim o estabelecimento escolar; b) a menor oferta da matrícula em Educação Infantil nos territórios mais vulneráveis, sendo insuficiente para atender a demanda; c) a tendência à homogeneidade do corpo discente em escolas localizadas nos territórios vulneráveis, com baixo acesso a recursos culturais e menor nível socioeconômico; d) as relações entre escolas, que tendem a competir por recursos humanos, alunos e docentes, e a evitarem ou a receberem alunos considerados problemas (os autores denominam de escolas de decantação aquelas, situadas em territórios de alta vulnerabilidade social, que tendem a acolher esse tipo de

3 O Índice de Desenvolvimento da Educação Básica (Ideb), expresso numa escala de 0 a 10, é calculado bianualmente pelo Instituto Nacional de Estudos e Pesquisas Anísio Teixeira (Inep), órgão governamental vinculado ao Ministério da Educação (MEC) para os anos iniciais do Ensino Fundamental $\left(1^{\circ}\right.$ ao $5^{\circ}$ ano), anos finais $\left(6^{\circ}\right.$ ao $\left.9^{\circ}\right)$ e para o Ensino Médio. Faz uso do desempenho dos alunos em Língua Portuguesa e Matemática em teste padronizado em âmbito nacional (Prova Brasil) e de taxas de aprovação.

4 A Prova Brasil faz parte do Sistema de Avaliação da Educação Básica (Saeb) e é um teste padronizado em âmbito nacional, uma avaliação externa censitária dos alunos da $4^{\mathrm{a}}$ série $/ 5^{\circ}$ ano e $8^{\mathrm{a}}$ série $/ 9^{\circ}$ ano do Ensino Fundamental das escolas públicas com, no mínimo, 20 alunos matriculados nas séries/anos citadas. Os alunos do universo fazem provas de Língua Portuguesa e Matemática, bem como respondem a um questionário que investiga suas características socioeconômicas e aspectos de suas aulas. Diretores e professores também respondem a um questionário. 
aluno e de processos de evitação, os mecanismos criados pelas escolas para não matricular ou excluir essas crianças de suas instituições). Outras pesquisas decorreram a partir das evidências encontradas sobre as relações de interdependência competitiva entre escolas. À literatura que trata da relação entre vulnerabilidade social do território/segregação residencial e desigualdade escolar, incorporaram-se referências sobre hierarquia de estabelecimentos e disputa de profissionais e familiares por escolas mais prestigiadas, tais como os de Delvaux (2005), o da European Commission (2004), os de Van Zanten (2005, 2006, 2009) e Van Zanten e Grospiron (2001), o de Yair (1996), os de Costa e Koslinski (2011, 2012), o de Resende et al. (2011), o de Nogueira, Resende e Vianna (2013) e o de Ben Ayed (2012). Essa literatura, de modo amplo, assevera que, num determinado sistema escolar, pode haver mecanismos de competição por recursos (alunos e professores de determinado perfil, escolas mais prestigiadas, dentre outros), sendo o aluno o recurso mais disputado.

Nesse sentido, Alves et al. (2015), em estudo exploratório, buscaram apreender processos e práticas relativos à interdependência competitiva entre escolas, utilizados por escolas públicas estaduais e municipais, localizadas em regiões predominantemente periféricas, num contexto de regulação que inibe tanto a escolha de estabelecimento de ensino pelas famílias como processos de seleção pelas escolas. A pesquisa buscou ainda apreender os princípios que orientavam esses processos e práticas de seleção, utilizando pesquisa de caráter qualitativo, empregando o procedimento de bola de neve, tendo como participantes os secretários de estabelecimentos de ensino encarregados das matrículas. A análise dos dados dessa pesquisa revelou a existência de dois processos: um deles caracteriza-se pela evitação de alunos, concretizado pela negação de cadastro no momento em que os familiares buscam se inscrever num sistema informatizado em busca de vagas ou pela não aceitação de matrículas, quando os solicitantes são avaliados como supostas ameaças à disciplina. $\mathrm{O}$ outro, pela expulsão velada, quando alunos indesejados são convidados a buscarem outro estabelecimento, devido a conflitos e a problemas de comportamento. Nos dois casos, o princípio gerador das práticas e dos processos reside na busca de assegurar um ambiente escolar disciplinado e revelam relações de interdependência competitiva entre escolas.

Embora, nesse estudo, o território não tenha sido demarcado, os dados indicam a existência de práticas de evitamento de certos alunos justificados por preconceitos e representações negativas sobre esses sujeitos e suas famílias: quando os alunos são moradores de favela, por exemplo, podem ser evitados como meio de garantir uma clientela mais adequada em termos de comportamento. Pesquisas de caráter quantitativo visando dimensionar o fenômeno seriam essenciais, especialmente se estabelecessem conexões entre tipos de 
relação estabelecidos entre escolas, vulnerabilidade social do território, pobreza e desigualdade escolar. Especialmente, porque a pesquisa de Alves et al. (2015) detectou práticas com o potencial para gerar escolas homogêneas, que agrupam alunos-problema que, devido ao efeito de pares, tenderão a desempenhos menos elevados, como mostra a literatura. Enquanto outras escolas, do mesmo território, poderão, livres dos alunos-problema (mais pobres, menos afeitos ao tipo de socialização escolar), apresentar desempenhos escolares mais elevados.

Tangerino-Silva (2016) investigou - em sua dissertação de mestrado, em duas escolas da mesma região vulnerável do município de São Paulo, estudada por Érnica e Batista (2012) - a relação de gestores escolares com mecanismos de interdependência competitiva entre escolas, se conhecem e se interagem com tais mecanismos. A autora investigou se gestores escolares conhecem e interagem com mecanismos de interdependência competitiva entre escolas. Para a autora, os gestores afirmaram a existência de processos de expulsão de alunos e já ouviram falar de práticas de evitamento de alunos em outras escolas. Também se mostram cientes da existência de uma hierarquia de prestígio entre escolas e afirmam que os pais tentam, embora afirmem ser difícil, conseguir, no momento da matrícula, escolher onde seus filhos estudarão e, assim, burlar o sistema de matrícula setorizada.

Esses dados corroboram Batista e Carvalho-Silva (2013) que denotaram que famílias de territórios bastante vulneráveis, mais proativas na escolarização dos filhos, buscam evitar a setorização da matrícula visando matricular seus filhos em escolas que consideram mais seguras e mais organizadas.

As opiniões sobre as [...] escolas mencionadas [pelas mães entrevistadas] evidenciam a existência de uma hierarquia estabelecida com base em alguns critérios. [...]. As escolas que conseguem assegurar a proteção dos filhos contra a violência e também a disciplina são, nas falas das mães, as [escolas] mais bem avaliadas, conforme afirma Lúcia: "A escola municipal B é uma escola segura e disciplinada. Fico sossegada com a Janaína lá”. (BATISTA; CARVALHO-SILVA, 2013, p. 46-47).

Batista e Carvalho-Silva (2013) trouxeram evidências de que as escolas são hierarquizadas segundo distintos critérios e que essa hierarquia estrutura alguma dimensão de competição entre famílias por escolas que consideram mais adequadas para seus filhos. E, ao que parece, são justamente aquelas mães que argumentam melhor ou que têm mais ativos sociais no território que estão em vantagem. Esse estudo corrobora a pesquisa de Nogueira, Resende 
e Vianna (2013) quando afirmam que há fatores distintos, para além daqueles tradicionalmente utilizados para expressar capital cultural, que interferem na hierarquização das escolas pelas famílias e nas suas disputas por escolas consideradas mais adequadas a seus interesses.

Ben Ayed (2012) afirma que, na França, pesquisas identificaram estratégias de escolas e famílias, de classe média, em busca de vantagens, situação que passa a compor a lista de fatores que acirram as desigualdades. $\mathrm{O}$ que as pesquisas, neste texto, analisadas evidenciam é a existência de ações de familiares em contexto de pobreza e vulnerabilidade social, voltadas ao objetivo de matricular os filhos em determinadas escolas. Ou seja, há indícios de que famílias com poucos recursos socioculturais também podem se mobilizar em busca de escolas que lhes pareçam mais adequadas.

Com base em Érnica e Batista (2012), Alves et al. (2014) buscaram verificar se a desigualdade socioespacial e a composição sociocultural dos alunos interferem na alocação de professores na rede municipal da cidade de São Paulo. Ou seja, se nos processos de disputas de professores por escolas, há alguma influência da vulnerabilidade social do território. O estudo se apropriou do IPVS e dos setores censitários do IBGE, notificando assim diferenças de vulnerabilidade social no âmbito de um território de alta vulnerabilidade social da cidade de São Paulo. Os procedimentos metodológicos foram os seguintes: escolha de um território considerado de alta vulnerabilidade social na cidade de São Paulo; análise das remoções dos professores que tinham alguma relação com o território de São Miguel Paulista, ocorridas ao longo de cinco anos; uso do IPVS, cujos indicadores se propõem a extrapolar as medidas de pobreza, conforme as justificativas daqueles que consideram que vulnerabilidade social é mais própria para compreender a complexidade da desigualdade nos grandes centros urbanos. Por meio desse índice, foram calculados níveis de vulnerabilidade da vizinhança das escolas do território; mensurou-se também o nível de heterogeneidade/homogeneidade dos alunos no que tange aos seus recursos socioeconômicos das escolas da região selecionada. Para tanto, foram usadas informações dos questionários associados à Prova Brasil, respondidos pelos alunos, com os quais se elaborou um índice de heterogeneidade dos alunos; combinaram-se então as informações provenientes do IPVS (que classificou o nível de vulnerabilidade das escolas) e do índice de heterogeneidade dos alunos, gerando nove tipos de escolas presentes no território.

Critérios de seleção dos concursos de remoção - tempo de carreira do professor e sua formação - permitiram que se tratasse do capital profissional dos professores. Esses foram diferenciados, segundo tais critérios, por meio de quartis que iam daquele que continha os professores mais bem pontuados nos concursos (maior capital profissional) - Q1, àqueles que continham os 
professores com menor capital profissional - Q4. Os quartis 2 e 3 continham professores com níveis medianos de capital profissional.

A pesquisa concluiu que, nas trocas de professores de uma mesma subprefeitura e demais regiões de São Paulo, a maioria dos ingressantes na subprefeitura do estudo está entre os professores com menor capital profissional. Os docentes com maior capital profissional quando entram escolhem, em sua maioria, escolas de entorno menos vulnerável e que concentram alunos com maiores recursos culturais. Nas trocas internas, a maioria, que trabalhava em escolas com entorno mais vulnerável e com alunos de recursos socioculturais baixos ou heterogêneos, migrou para escolas de vizinhança menos vulnerável e com estudantes de mais alto recurso sociocultural.

Os resultados dessa pesquisa apontam para vínculos entre desigualdades socioespaciais, desigualdades sociais, interdependência competitiva entre escolas e desigualdade escolar (considerada pelas diferenças de distribuição da qualidade do recurso mais relevante para a consecução da qualidade da educação, o professor com mais formação e experiência) em uma região considerada mais vulnerável quando se compara as diversas zonas de vulnerabilidade da cidade de São Paulo. Darling-Hammond (2014), após meta-pesquisa sobre estudos nos últimos 30 anos nos Estados Unidos, afirma que a formação e experiência do professor são fatores relevantes para o desempenho dos alunos. Com base nessa autora, é possível afirmar que a situação demarcada pela pesquisa acima pode gerar desigualdade escolar, do ponto de vista da criação de diferenças de desempenho de escolas situadas em territórios de distintos níveis de vulnerabilidade social, com desvantagem para as localizadas nas regiões mais vulneráveis.

Breches (2015) analisou o que professoras dos terceiros anos do Ensino Fundamental dizem sobre formação continuada e também seus apontamentos sobre práticas de formação continuada que realizaram ou que realizam na escola em que atuam. $\mathrm{O}$ autor buscou também identificar lacunas, dificuldades expressas por essas professoras para a realização do seu trabalho. Breches (2015) afirma que os professores entrevistados realizam formação continuada por meio da troca informal entre pares, no vácuo deixado pela impossibilidade de participação dos momentos formais de formação. Os dados das entrevistas indicam ainda que a não participação da maioria das professoras entrevistadas da jornada de formação continuada ocorre ou por razões vinculadas à ausência de condições adequadas de trabalho ou por dificuldades de ordem pessoal. Para ele, portanto, o ensino pode estar sendo prejudicado, pois, a troca informal entre pares é insuficiente para os professores uma vez que estes afirmam terem dificuldades conceituais face às exigências do processo de alfabetização e também para fazer a gestão do comportamento dos alunos na sala de aula.

Marcucci (2015), interessada em observar a qualidade das oportunidades 
educacionais no processo de alfabetização, em escola de território vulnerável, propôs-se a realizar estudo de caso sobre a gestão do tempo, a estrutura organizacional da aula e os objetos de ensino em Língua Portuguesa. Em seu estudo, baseado em fontes variadas, como a observação participante de aulas de $3^{\circ}$ ano, coleta de cadernos escolares e planos de aula e entrevistas semiestruturadas com as professoras, concluiu que há variações negativas entre a escola-participante e o que está estabelecido para o conjunto de escolas que pertencem a um mesmo sistema de ensino. Em relação à gestão do tempo atribuído às aulas, por exemplo, consagra-se menos tempo ao ensino do que o estabelecido, o que denota desigualdade em termos de ocasião para aprender. Quanto ao que se ensina em Língua Portuguesa, há também diferenças, com o privilégio de certos eixos de conteúdo em detrimento de outros fundamentais na alfabetização, bem como a análise de aulas de Língua Portuguesa, cuja estrutura organizacional pouco colabora para a apropriação e desenvolvimento de conhecimentos e capacidades, especialmente por alunos pouco familiarizados com a forma escolar e seu modo de organização do ensino.

Esses estudos permitem levantar hipóteses relativas à influência da vulnerabilidade social do território sobre as oportunidades educacionais. Érnica e Batista (2012) afirmaram que, nos territórios mais vulneráveis do município de São Paulo, o desempenho dos alunos, medido pela Prova Brasil, é menor. Koslinski, Alves e Lange (2013) evidenciaram que, na geografia da cidade do Rio de Janeiro, as áreas periféricas e as comunidades situadas nos bairros menos abastados apresentaram resultados educacionais inferiores à área central e aos bairros nobres.

Ribeiro e Koslinski (2009) estudaram o desempenho escolar de alunos de $4^{\circ}$ e $9^{\circ}$ anos da rede pública de ensino do Rio de Janeiro e sua relação com o modo como o espaço encontra-se, nessa cidade, apropriado socialmente. Os autores controlaram a origem socioeconômica dos alunos e as características das escolas. O contexto social do território foi apreendido por meio das variáveis clima educativo (entendido como a média da escolaridade domiciliar dos adultos acima de 25 anos de idade) e da identificação das escolas próximas em até 100 metros de favelas. Os autores detectaram pior desempenho entre os alunos de escolas com entornos menos favorecidos e com domicílios de menor clima educativo; afirmaram que as favelas têm seus resultados educacionais impactados negativamente devido ao isolamento social que lhes é peculiar.

Torres et al. (2008) analisaram desigualdades educacionais nas escolas públicas da cidade de São Paulo, considerando as diferenças entre as que se localizam em áreas centrais e em áreas periféricas. Argumentam que, mesmo após o controle estatístico de variáveis tradicionalmente associadas às desigualdades escolares (renda familiar, escolaridade dos pais, sexo, raça), persistem 
desigualdades entre indivíduos com características sociais similares, porém residentes em regiões diferentes.

Os piores resultados educacionais seriam dos alunos que estudam em escolas situadas em territórios de alta vulnerabilidade social, relacionados não apenas às condições de vida, de moradia, de acesso aos serviços e informações e trabalho dos familiares, mas também ao que se passa no interior das escolas existentes nesses territórios e ao tipo de política que aí são implementadas?

Torres et al. (2008) buscaram compreender até que ponto as instituições e as políticas educacionais contribuem para a produção da desigualdade escolar. Identificaram os seguintes mecanismos institucionais que a produzem: as normas de alocação dos profissionais no sistema estadual e municipal que fazem com que professores que obtiveram baixa pontuação nos concursos públicos ou que acabaram de ingressar na carreira se dirijam às escolas da periferia, resultado que corrobora Alves et al. (2014): maior incidência, nas regiões periféricas, de professores substitutos e temporários, e também rotatividade dos professores nas escolas.

No que tange ao modelo de papéis sociais, Torres et al. (2008) evidenciaram apreciações valorativas negativas sobre os estudantes oriundos de famílias pobres, presentes majoritariamente nas regiões periféricas: para os profissionais da educação, essa população estaria mais interessada nos benefícios sociais (alimentação, sobretudo) do que na educação escolar. Careceria de higiene, de hábitos sociais e de valores estimados pela escola. A opinião dos professores é a de que, dados o entorno social e a família, dificilmente o trabalho na sala de aula gerará aprendizagem e mudança no comportamento. A expectativa dos professores em relação ao futuro dos alunos, segundo essa pesquisa, é bastante baixa.

Barbosa e Sant'Anna (2010), em pesquisa na cidade do Rio de Janeiro, visaram identificar fatores sociais que interferem na constituição de formas de valorização da educação escolar, considerando também variáveis relativas à distinção entre territórios. Contrariando hipóteses iniciais, as autoras não constataram diferença no desempenho dos alunos que viviam nas favelas daqueles que viviam em "bairros menos pobres". Entretanto, os alunos que estudam em escolas de favelas distantes do centro da cidade apresentaram desempenho pior que os que estudavam em favelas próximas a ele. O nível de qualidade da oferta em escolas situadas em favelas mais distantes do centro da cidade, medido por meio de um índice elaborado pela pesquisa, é bem inferior ao nível de qualidade da oferta em escolas de favelas que ficam em regiões próximas à região central. Desse modo, afirmaram que "o fato de estar na favela afeta o desempenho escolar somente se juntarmos outra variável espacial, a distância do Centro da cidade". (BARBOSA; SANT'ANNA, 2010, p. 171).

Barbosa e Sant'Anna concluem que as famílias que vivem nas favelas mais distantes tendem a valorizar mais a educação escolar. E essa valorização 
está vinculada à utilidade da escola enquanto meio de alcance de posições sociais mais vantajosas para seus filhos. As pesquisadoras evidenciaram que são as famílias que têm filhos com pior desempenho que atribuem mais valor à escola: moradoras de favelas mais distantes, aquelas que têm empregos mais precários, trabalhadores manuais, pessoas menos escolarizadas. Ainda de acordo com Barbosa e Sant'Anna, quanto mais distante das regiões centrais da cidade está uma favela, mais distantes estarão suas escolas de melhores condições de funcionamento, o que reafirmaria a segregação residencial como "um mecanismo que dificulta a superação (via educação) do quadro de precariedade no qual vivem moradores de espaços segregados" (BARBOSA; SANT'ANNA, 2010, p. 173). As autoras afirmam que "as escolas da [...] amostra parecem incapazes de valorizar esse capital social [familiar] - o valor atribuído à educação" pelas famílias que vivem em territórios mais vulneráveis. (BARBOSA; SANT'ANNA, 2010, p. 174).

Batista e Carvalho-Silva (2013) trouxeram evidências que confrontam a ideia disseminada no meio educacional brasileiro de que as famílias pobres são, muitas vezes, ausentes no processo de escolarização de suas crianças e adolescentes. Os autores mostram, em pesquisa qualitativa, que famílias - pobres, com poucas referências do universo escolar e moradoras de territórios segregados - empreendem, com seus recursos, esforços na escolarização dos filhos. Porém, quando a situação de vulnerabilidade social de uma família se intensifica muito, com sobreposição de grandes dificuldades relativas a trabalho, saúde e moradia, a possibilidade de empreender iniciativas pela escolarização pode ficar comprometida.

Com base em Torres et al. (2008), Alves et al. $(2014,2015)$ e Tangerino-Silva (2016), pode-se indicar evidências de que as políticas educacionais no município de São Paulo agem negativamente sobre a segregação residencial de distintas formas: por diferenciações advindas de distintas políticas realizadas pelas redes ensino municipal e estadual; pelas representações e expectativas negativas que os professores têm dos alunos residentes em territórios vulneráveis ou da periferia da cidade; pelas legislações que regulamentam a alocação dos professores nas redes. Conforme se viu anteriormente, professores com maior capital profissional vão ao encontro de alunos com maiores recursos culturais, matriculados em escolas de territórios menos vulneráveis; os alunos com menor capital sociocultural, cujos pais têm menos conhecimento do tipo de capital social valorizado pela escola, que desconhecem seus direitos e residem em territórios mais estigmatizados, como favelas, podem ser preteridos em momentos de matrícula, dificultando seu acesso às escolas mais prestigiadas ou mesmo a qualquer outra escola. Em atos de expulsão de alunos, esses estigmas podem também contribuir para a decisão, uma vez que escolas parecem buscar alunos 
mais adaptados à sua busca por um ambiente escolar menos conturbado. Ao executar tais mecanismos, escolas poderão reproduzir, no sistema educacional, a desigualdade social, "empurrando" alunos mais pobres, de regiões mais vulneráveis, para escolas com menor prestígio junto aos pais menos afeitos a lutar por seus direitos e/ou pelas escolas de maior prestígio.

Há indícios também, a partir de Marcucci (2015) e Breches (2015), de que haja problemas de efetividade das políticas de formação continuada de professores. Evidenciam-se lacunas, tanto nas práticas de professores quanto na sua formação, num tipo de escola que, segundo a literatura, exigiria um professor com capacidade de lidar com situações complexas, como é o caso de escolas cujo entorno é de vulnerabilidade social. Esse professor se sente despreparado para ensinar, fazer a gestão tanto do tempo nas aulas quanto da disciplina dos alunos.

Diante da relevância de se enfrentar a desigualdade escolar no país, importante chamar a atenção para a dificuldade da escola de valorizar o capital social de famílias em situação de vulnerabilidade social: seja quando esse capital se manifesta na forma de valorização da utilidade da escola, seja quando se expressa no esforço das famílias de territórios vulneráveis, pela escolarização dos filhos.

Pode-se dizer, portanto, que os resultados das pesquisas apontam para a existência de vínculos entre desigualdades socioespaciais (indicadas pela interface entre sobreposição de desigualdades e segregação social no território), desigualdades sociais (indicadas pelos níveis de recursos socioeconômicos e culturais dos alunos e famílias) e desigualdade escolar (vista pelos resultados educacionais, expectativa sobre os alunos, formação e experiência dos professores e pela infraestrutura das escolas). Interface entre vulnerabilidade social no território e o fenômeno da interdependência competitiva entre escolas começa também a se evidenciar, por meio de estudos exploratórios, indicando presença de vantagem de algumas escolas de territórios menos vulneráveis em detrimento de outras localizadas em regiões mais vulneráveis. Há indícios de que essa vantagem estaria na captação de professores com maior capital profissional e experiência; na evitação e expulsão de alunos de perfil avaliado como conturbador do ambiente escolar; e também em ações de familiares - que possuem mais recursos - em busca de escolas mais adequadas aos seus interesses.

\section{Considerações finais}

Embora as pesquisas que buscam compreender as conexões entre vulnerabilidade social do território e desigualdade escolar no país sejam recentes, 
exploratórias e careçam de acúmulo que apoie afirmações mais robustas, elas podem gerar reflexões sobre o tipo de política educacional e prática escolar com potencial para fortalecer ou dirimir a desigualdade escolar. Conhecimento relevante face ao objetivo de ampliar as oportunidades educacionais junto àqueles que têm mais dificuldades no acesso ao conhecimento ofertado nas instituições escolares.

Os resultados da análise dos estudos tratados neste texto denotam complexidade na produção das desigualdades escolares em grandes cidades do país. Trazem indícios de que aspectos que dizem respeito à moradia, às representações sociais, aos contornos de políticas educacionais, à falta de investimento público e de segurança, à fragilidade na formação continuada dos professores e dificuldades relativas ao ensino e à gestão da sala de aula podem, num contexto desfavorável, gerar práticas desvantajosas para as populações mais pobres e distantes do universo escolar, que vivem nos territórios mais vulneráveis.

Tais resultados indicam que o enfrentamento da desigualdade escolar que se produz em contextos de vulnerabilidade social nos territórios das grandes cidades exigiria mudanças profundas e amplos esforços na implementação das políticas educacionais, inclusive para integração com políticas de outras áreas. Dada a dificuldade de concertação dos diversos entes federados e órgãos públicos na consecução da educação no país, impõe-se reflexões sobre a amplitude dos desafios para o aumento da equidade e qualidade da educação brasileira.

Por fim, cabe ainda mencionar que a análise realizada denota que os estudos sobre o fenômeno aqui abordados fazem uso de distintos referenciais teóricos e metodologias. Seria profícuo, posteriormente, discutir a repercussão dessas distintas referências sobre os resultados encontrados.

\section{REFERÊNCIAS}

ALVES, L. et al. Remoção de professores e desigualdades em territórios vulneráveis. Cadernos Cenpec. v. 4, n. 2, p. 122-145, 2014.

ALVES, L. et al. Seleção velada em escolas públicas: práticas, processos e princípios geradores. Educação e Pesquisa, São Paulo, v. 41, n. 1, p. 137-152, jan./mar. 2015.

BARBOSA, L. O.; SANT'ANNA, M. J. G. As classes populares e valorização da educação no Brasil. In: RIBEIRO, L. C. Q. et al. Desigualdades Urbanas, desigualdades escolares. Rio de Janeiro: Letra Capital: Observatório das Metrópoles, IPPUR/UFRJ, 2010. p. 155-174. 
BATISTA, A. A. G.; CARVALHO-SILVA, H. Família, escola, território vulnerável. São Paulo: Cenpec, 2013.

BEN AYED, C. As desigualdades socioespaciais de acesso aos saberes: uma perspectiva de renovação da sociologia das desigualdades escolares? Educação e Sociedade, Campinas, v. 33, n. 120, p. 783-803, jul-set. 2012.

BEN AYED, C.; BROCCOLICHI, S. Quels liens entre réussite scolaire, inégalités sociales et lieu de scolarisation? Revue Ville École Intégration Diversité, Paris, n. 155, p. 66-71, dez. 2008.

BRECHES, B. Formação continuada em uma escola de território vulnerável do município de São Paulo. Dissertação (Mestrado em Educação) - Universidade Cidade de São Paulo, São Paulo. 2015.

COSTA, M.; KOSLINSKI, M. Quase-mercado oculto: disputa por escolas "comuns" no Rio de Janeiro. Cadernos de Pesquisa, São Paulo, v. 41, n. 142, jan./abr., p. 246-266, 2011.

COSTA, M.; KOSLINSKI, M. Escolha, estratégia e competição por escolas públicas. Pro-Posições, Campinas, v. 23, n. 2, p. 195-213, maio/ago. 2012.

DARLING-HAMMOND, L. A importância da formação docente. Cadernos Cenpec, v. 4, n. 2, p. 230-247, 2014.

DELVAUX, B. Méthode de définition des espaces d'interdependance entre écoles. Les Cahiers du Cerisis, Louvain, n. 24, jan. 2005.

ÉRNICA, M.; BATISTA, A. A. G. A escola, a metrópole e a vizinhança vulnerável. Cadernos de Pesquisa, São Paulo, v. 42, n. 146, p. 640-666, maio/ago. 2012.

EUROPEAN COMMISSION. Changes in regulation modes and social production of inequalities in education systems: a European comparison. Luxemburgo, 2004. Disponível em: $<\mathrm{http}$ ///ec.europa.eu/research/social-sciences/pdf/reguleducnetwork-final-report_en.pdf $>$. Acesso em: 20 mar. 2014.

KAZTMAN, R. Seducidos y abandonados: el aislamiento social de los pobres urbanos. Revista de la CEPAL, Chile, n. 75, p. 171-189, dec. 2001.

KOSLINSKI, M.; ALVES, F. Novos olhares para as desigualdades de oportunidades educacionais: a segregação residencial e a relação favela-asfalto no contexto carioca. Educação e Sociedade, Campinas, v. 33, n. 120, p. 805-831, jul./set. 2012.

KOSLINSKI, M. C.; ALVES, F.; LANGE, W. Desigualdades educacionais em contextos urbanos: um estudo da geografia de oportunidades educacionais na cidade do Rio de Janeiro. Educação \& Sociedade, v. 34, p. 1175-1202, 2013.

MARCUCCI, F. A educação nas grandes metrópoles: ensino de Língua Portuguesa em São Miguel Paulista. Dissertação (Mestrado em Educação e Saúde na Infância e na Adolescência) - Escola de Filosofia, Letras e Ciências Humanas, Universidade Federal de São Paulo. 2015. 
NOGUEIRA, C. M.; RESENDE, T. F.; VIANNA, M. J. B. Escolha do estabelecimento de ensino, mobilização familiar e desempenho escolar: um estudo com famílias de alunos da rede pública de Belo Horizonte. Belo Horizonte. Faculdade de Educação da UFMG, 2013.

OBSERVATÓRIO DAS METRÓPOLES. Instituto Nacional da Ciência e da Tecnologia. Disponível em: $<$ http://www.observatoriodasmetropoles.net/index.php?option=com_co ntent\&view=article\&id=202\&Itemid=62> . Acesso em 29 abr. 2015.

PEREIRA-SILVA, C. Vulnerabilidade social nos territórios das grandes cidades, educação e o princípio de justiça como equidade na escola. Dissertação (Mestrado em Educação) - Universidade Cidade de São Paulo, São Paulo. 2016.

RESENDE, T. F. et al. Escolha do estabelecimento de ensino e perfis familiares: uma faceta a mais das desigualdades escolares. Educação e Sociedade, Campinas, v. 32, n. 117, p. 953-970, out./dez. 2011.

RIBEIRO, L. C. Q.; KOSLINSKI, M. C. A Cidade contra a escola? O caso do município do Rio de Janeiro. Revista Contemporânea de Educação, Rio de Janeiro, v. 4, n. 8, p. 221-233, ago./dez. 2009.

TANGERINO-SILVA, N. T. Interdependência competitiva entre escolas e gestão escolar num território vulnerável. Dissertação (Mestrado em Educação) - Universidade Cidade de São Paulo, São Paulo. 2016.

TORRES, H. G. et al. Educação na Periferia de São Paulo: ou como pensar as desigualdades educacionais? In: RIBEIRO, L. C. Q. KAZTMAN, R. (Orgs.) A Cidade contra a Escola?: segregação urbana e desigualdades educacionais em grandes cidades da América Latina. Rio de Janeiro: Letra Capital, FAPERJ, IPPES, 2008.

VAN ZANTEN, A. Efeitos da concorrência sobre a atividade dos estabelecimentos escolares. Cadernos de Pesquisa, São Paulo, v. 35, n. 126, pp. 565-593, set./dez. 2005.

VAN ZANTEN, A. Compétition et fonctionnement des établissements scolaires: les enseignements d'une enquête européenne. Revue française de pédagogie, Lyon, n. 156, p. 9-17, juil/sept. 2006.

VAN ZANTEN, A. Choisir son école. Stratégies familiales et médiations locales. Paris: PUF, 2009.

VAN ZANTEN, A.; GROSPIRON, M-F. Les carrières enseignantes dans les établissements difficiles: fuite, adaptation et développement professionnel. VEI Enjeux, Paris, n. 124, p. 71-93, mars 2001.

YAIR, G. School organization and market ecology: a realist sociological look at the infrastructure of school choice. British Journal of Sociology of Education, London, Routledge, v. 17, n. 4, p. 453-471, 1996.

Texto recebido em 23 de março de 2017.

Texto aprovado em 12 de abril de 2017. 
